\title{
An Exploratory Study of the Determinants of Adherence to Antiretroviral Therapy by Adolescents and Youths in the Eastern Cape, South Africa
}

\author{
Bulelwa Frieda Mayeye ${ }^{1}$, Daniel Ter Goon ${ }^{1} \&$ Elizabeth Matise Yako ${ }^{1}$ \\ ${ }^{1}$ Department of Nursing Science, Faculty of Health Sciences, University of Fort Hare, East London, South \\ Africa \\ Correspondence: Daniel Ter Goon, Department of Nursing Science, Faculty of Health Sciences, University of Fort \\ Hare, East London, South Africa.
}

Received: April 16, 2019 Accepted: June 18, 2019 Online Published: September 17, 2019

doi:10.5539/gjhs.v11n11p141 URL: https://doi.org/10.5539/gjhs.v11n11p141

\begin{abstract}
It is important to understand the factors affecting willingness of adolescents and youths to adhere to antiretroviral therapy (ART) in order to ensure positive treatment outcomes. Drawing on the Health Belief Model (HBM) theory, this study investigated the influence of self-efficacy and perceived benefits on the adherence to ART medications among adolescents and youths in Buffalo City Metropolitan Municipality (BCMM) District, Eastern Cape, South Africa. A purposive sample of $206 \mathrm{HIV}$ positive adolescents and youth between age 14 to 24 years receiving ART in Buffalo City Metropolitan Municipality were interviewed using a self- administered questionnaire covering treatment benefits and self-efficacy. The majority of the participants affirmed strict adherence to the treatment plan is essential for effective ARV treatment (69.4\%). The participants always take their medication on schedule $(88.8 \%)$. It was found that a significant relationship exists between self-efficacy and adherence to ART $(p=0.000)$. The results suggest that perceived benefits and self-efficacy are a predictor of adherence to ART by adolescents and youths, at least in this setting.
\end{abstract}

Keywords: adolescents and youths, antiretroviral therapy, adherence, Health Belief Model

\section{Introduction}

Global coverage of antiretroviral therapy reached 46\% [43-50\%] at the end of 2015 and South Africa alone had nearly 3.4 million people on treatment, more than any other country in the world amongst which the majority were adolescents and youths ((UNAIDS, 2016).

However, adhering to the treatment instructions for a long-term illness poses a great challenge to the client, especially adolescents (World Health Organization, 2006a). In public health centres it is observed that most adolescents and youths do not regularly attend the clinic to collect their ART. An increase loss to follow - up among the adolescents and youths is noticeable.

Antiretroviral adherence in young children and adolescents poses unique and formidable challenges (Rudy, Murphy, Harris, Muenz, \& Ellen, 2009). The desire for autonomy and independence, risk-taking behaviours, preoccupation with self-image, and the need to fit in with their peers makes it difficult for adolescents and youths to adhere to ART. It is therefore challenging to attract and sustain adolescents' focus on maintaining their health, particularly for those with chronic illnesses (Tanner, Philbin, Duval, Ellen, Kapogiannis, \& Fortenberr, 2014). Inconsistent adherence to ART may result in the development of resistant strains in a patient resistance

There are few studies on ART adherence among adolescents and youths in the South African context, applying the Health Belief Model as stated by various authors (Munro, Lewin, Swart, \& Volmink, 2007; Barclay, Hinkin, Castellon, Mason, Reinhard, Marion, \& Durvasula, 2007). Therefore, it is important to determine the HBM constructs and the psychosocial determinants of ART adherence in the South African context to guide interventions geared towards promoting ART adherence among adolescents and youths. The constructs of HBM address long-term medication adherence, and the influence of socio-psychological factors. Few of the many interventions developed to address this issue explicitly draw on theories of health behaviour in relation to adolescent health in South Africa. Such theories could contribute to the design of more effective interventions to promote treatment adherence by adolescents, and to improve assessments of the transferability of these 
interventions across different health issues and settings. The HBM assumes that a person will take a health-related action if that person feels or believes (has a positive expectation) that a negative health condition can be avoided. (Glanz, Rimer, \& Lewis, 2002). The major components of this model are perceived susceptibility (belief about getting a disease or condition), perceived severity (belief about the seriousness of the condition), perceived benefits( belief about the potential positive aspects of a health action) perceived barriers (belief about the potential negative aspects of a health action), cues to action ( events, people or things that move people to change behaviour) and self-efficacy (belief that one can achieve the behaviour required to execute the outcome) (Hayden, 2009; Stanhope \& Lancaster, 2005). This study investigated adherence to ART medications benefits and self-efficacy among adolescents and youths in Buffalo City Metropolitan Municipality (BCMM) District, Eastern Cape, South Africa.

\section{Methodology}

\subsection{Research Design}

This was a quantitative exploratory survey of HIV positive adolescents and youths between 14 to 24 years receiving ART in health facilities in BCMM. The BCMM population consists largely of isi-Xhosa speaking people. High unemployment and pregnancy rates are experienced by adolescents and youths and are mostly depending on child support rate for their livelihood (Mchunu, Peltzer, Tutshana, \& Seutlwadi, 2012). The Buffalo City Metropolitan Health District is composed of 5 Community Health Centres, 72 Primary Health clinics, 2 provincial tertiary hospitals (namely Frere and Cecilia Makhiwane), and 2 District Hospitals (namely Bhisho and Grey) and 12 mobile services.

\subsection{Sampling}

A purposive sample of 206 adolescents and youths attending ARV clinics in 18 health facilities during the study period participated in the study. Purposive sampling was used to select participants who are receiving ARVs. Seven primary health clinics were selected from Mdantsane sub-district (peri-urban), 5 from East London sub-district (urban), 3 from rural clinics, Frere Hospital (urban), Cecilia Maikine Hospital (semi-urban), 3 Community Health Centres, namely Nontyatyambo, Duncan Day and at Empilweni. Data were collected from August -November 2017.

\subsection{Research Instrument}

The Adherence Determinants Questionnaire (ADQ) scale, previously developed and validated (Barclay et al., 2007; DiMatteo et al., 1993), was used to measure participants' adherence to ART and self-efficacy. The questionnaire was adapted to the South African context.

\subsection{Ethical Considerations}

Ethical approval was obtained from the University of Fort Hare Research and Ethics Committee (YAKO51SMAY01). Permission to conduct the study was obtained from the Research Coordinator of the Research and Epidemiological Unit, Department of Health, Bhisho. Permission to access the clients at the health care centre was requested and obtained from the BCMM sub-district managers. Informed consent was obtained from participants prior to data collection. Parents/guardians of participants less than 18 years signed informed consent forms on their behalf. In addition, assent was obtained from the minors before data collection. A psychologist was available to offer psychological support during interview sessions. The anonymity and confidentiality of all the research participants was ensured by concealing the identity of the participants.

\subsection{Data Analysis}

Descriptive statistics, including percentages, means, standard deviation, and frequency distributions were used to summarize the data. Chi-square statistic was applied to determine the relationship between self-efficacy and demographic characteristics. A p-value of 0.05 was considered statistically significant. The Statistical Package for Social Sciences (SPSS version 22.0) was used for statistical analyses.

\section{Results}

The demographic characteristics of the participants (Table 1) indicates that majority of the participants were females (79.6\%), aged between 22 to 24 years (45.6\%), Africans $(88.3 \%)$, single $(90.7 \%)$, living with other adults (92.7\%), and attended high school but did not complete secondary schooling (40.8\%). Most of the participants were students $(49.5 \%)$ or were unemployed $(42.7 \%)$. The majority of the participants were residing in urban settings $(76.7 \%)$. 
Table 1. Demographic characteristics of the participants

\begin{tabular}{|c|c|c|}
\hline Variables & Frequency & Percentage \\
\hline \multicolumn{3}{|l|}{ Gender } \\
\hline Male & 42 & 20.4 \\
\hline Female & 164 & 79.6 \\
\hline \multicolumn{3}{|l|}{ Age (years) } \\
\hline $10-17$ & 65 & 31.6 \\
\hline $18-21$ & 47 & 22.8 \\
\hline $22-24$ & 94 & 45.6 \\
\hline \multicolumn{3}{|l|}{ Race } \\
\hline African & 182 & 88.3 \\
\hline Coloured & 24 & 11.7 \\
\hline \multicolumn{3}{|l|}{ Marital status } \\
\hline Single & 186 & 90.7 \\
\hline Widowed & 4 & 2.0 \\
\hline Divorced & 3 & 1.5 \\
\hline Married/living together & 12 & 5.9 \\
\hline \multicolumn{3}{|l|}{ Living situation } \\
\hline Live alone & 7 & 3.4 \\
\hline Live with other adults & 191 & 92.7 \\
\hline Live children and other adults & 8 & 3.9 \\
\hline \multicolumn{3}{|l|}{ Highest level of education } \\
\hline No formal education & 4 & 1.9 \\
\hline Completed primary school & 58 & 28.2 \\
\hline Attended high school but did not complete secondary & 84 & 40.8 \\
\hline Completed secondary & 60 & 29.1 \\
\hline \multicolumn{3}{|l|}{ Current work situation } \\
\hline Employed & 16 & 7.8 \\
\hline Student & 102 & 49.5 \\
\hline Unemployed & 88 & 42.7 \\
\hline \multicolumn{3}{|l|}{ Place residence } \\
\hline Urban & 158 & 76.7 \\
\hline Rural & 48 & 23.3 \\
\hline \multicolumn{3}{|l|}{ First language } \\
\hline Xhosa & 200 & 97.1 \\
\hline Afrikaans & 5 & 2.4 \\
\hline Isizulu & 1 & 0.5 \\
\hline \multicolumn{3}{|l|}{ Other languages } \\
\hline English & 176 & 85 \\
\hline English and Afrikaans & 13 & 6.5 \\
\hline English and Xhosa & 3 & 1.5 \\
\hline English and Sesotho & 2 & 1.0 \\
\hline English and Setswana & 1 & 0.5 \\
\hline English and IsiZulu & 9 & 4.5 \\
\hline Afrikaans & 2 & 1.0 \\
\hline
\end{tabular}




\subsection{Perception About Treatment Benefits}

Perceptions of the participants about treatment benefits (Table 2) indicates that the majority of the participants affirmed strict adherence to the treatment plan is essential for effective ARV $(143 ; 69.4 \%)$. Regular taking of ARVs drugs was perceived to be critical for the drugs to be effective (116; 56.3\%).

Table 2. Participants' perception concerning treatment benefits

\begin{tabular}{|c|c|c|c|c|c|}
\hline Statements & $\begin{array}{l}\text { SD } \\
\text { n(\%) }\end{array}$ & $\begin{array}{l}\text { D } \\
\mathbf{n}(\%)\end{array}$ & $\begin{array}{l}\mathbf{N} \\
\mathbf{n}(\%)\end{array}$ & $\begin{array}{l}\text { A } \\
\mathbf{n}(\%)\end{array}$ & $\begin{array}{l}\text { SA } \\
\mathbf{n}(\%)\end{array}$ \\
\hline Following my treatment plan will help me to be healthy & $0(0.0)$ & $1(0.5)$ & $2(1.0)$ & $114(55.6)$ & $88(42.9)$ \\
\hline $\begin{array}{l}\text { I realised that strict adherence to the treatment plan is essential for ARV } \\
\text { treatment to be effective }\end{array}$ & $2(1.0)$ & $5(2.4)$ & $1(0.5)$ & $143(69.4)$ & $55(26.7)$ \\
\hline ARV drugs will not be effective if I do not take them regularly & $4(1.9)$ & $13(6.3)$ & $5(2.4)$ & $116(56.3)$ & $68(33.0)$ \\
\hline
\end{tabular}

$\mathrm{SD}=$ Strongly agree; $\mathrm{D}=$ Disagree; $\mathrm{N}=$ Neutral; $\mathrm{A}=$ Agree; $\mathrm{SA}=$ Strongly agree .

\subsection{Self- Efficacy}

The participants expressed the view that they are always determined to do anything to take their medication on schedule $(183 ; 88.8 \%)$, including adhering to the treatment plan as a means of helping them to remember taking medication as prescribed $(190 ; 92.2 \%)$, and being committed to taking their medication, without minding the taste $(189 ; 92.2 \%)$ (Table 3).

Table 3. Participants' perceptions of self-efficacy in taking ART medications

\begin{tabular}{|c|c|c|c|c|}
\hline Statements & $\begin{array}{l}\text { N } \\
\text { n (\%) }\end{array}$ & $\begin{array}{l}\text { S } \\
(\mathrm{n}(\%)\end{array}$ & $\begin{array}{l}\text { M } \\
\text { n }(\%\end{array}$ & $\begin{array}{l}\text { A } \\
\text { n (\%) }\end{array}$ \\
\hline I fear that I am not capable of taking my medications as I should & $165(80.1)$ & $30(14.6)$ & $8(3.9)$ & $3(1.5)$ \\
\hline I worry that I will not be able to make the effort to take this medicine forever & $155(75.2)$ & $38(18.4)$ & $9(4.4)$ & $4(1.9)$ \\
\hline $\begin{array}{l}\text { No matter how hard I try, I don't think I will be able to follow my medications } \\
\text { schedule }\end{array}$ & $171(83.4)$ & $23(11.2)$ & $6(2.9)$ & $5(2.4)$ \\
\hline I am determined to do whatever it takes to take my medication on schedule & $11(5.3)$ & $3(1.5)$ & $9(4.4)$ & $183(88.8)$ \\
\hline I am determined to take my medications even if there is privacy & $32(15.5)$ & $19(9.2)$ & 23(11.2) & $132(64.1)$ \\
\hline $\begin{array}{l}\text { I am determined to stick with a plan to help me remember to take my } \\
\text { medication as prescribed }\end{array}$ & $4(1.9)$ & $4(1.9)$ & $8(3.9)$ & 190(92.2) \\
\hline I learn as much as I can about my medications so I can take them as prescribed & $41(19.9)$ & $10(4.9)$ & $14(6.8)$ & $141(68.4)$ \\
\hline $\begin{array}{l}\text { I am committed to taking my medication even if it tastes bad or is hard to } \\
\text { swallow }\end{array}$ & $4(2.0)$ & $4(2.0)$ & $8(3.9)$ & $189(92.2)$ \\
\hline
\end{tabular}

$\mathrm{N}=$ Never; $\mathrm{S}=$ Sometimes; $\mathrm{M}=$ Most of the times; $\mathrm{A}=$ Always. 
Table 4. Relationship between self-efficacy and demographic characteristics

\begin{tabular}{|c|c|c|c|}
\hline Variables & Mean score & SD & p-value \\
\hline \multicolumn{4}{|l|}{ Gender } \\
\hline Male & 18.5 & 2.0 & 0.322 \\
\hline Female & 18.9 & 2.2 & \\
\hline \multicolumn{4}{|l|}{ Age (years) } \\
\hline $10-17$ & 18.5 & 2.3 & 0.233 \\
\hline $18-21$ & 18.8 & 2.3 & \\
\hline $22-24$ & 19.1 & 1.9 & \\
\hline \multicolumn{4}{|l|}{ Race } \\
\hline African & 18.9 & 2.0 & 0.014 \\
\hline Coloured & 17.8 & 2.6 & \\
\hline \multicolumn{4}{|l|}{ Marital status } \\
\hline Single & 18.9 & 1.9 & 0.438 \\
\hline Widowed & 18.3 & 1.5 & \\
\hline Divorced & 18.7 & 2.3 & \\
\hline Married/living together & 17.9 & 4.3 & \\
\hline \multicolumn{4}{|l|}{ Highest level of education } \\
\hline No formal education & 20.0 & 0.0 & 0.116 \\
\hline Completed primary & 18.4 & 2.3 & \\
\hline Attended high school but did not complete matric & 18.8 & 2.4 & \\
\hline Completed matric & 19.3 & 1.4 & \\
\hline \multicolumn{4}{|l|}{ Current work situation } \\
\hline Employed & 19.4 & 1.2 & 0.172 \\
\hline Student & 19.1 & 1.7 & \\
\hline Unemployed & 18.6 & 2.4 & \\
\hline \multicolumn{4}{|l|}{ Place of residence } \\
\hline Rural & 18.9 & 1.9 & 0.438 \\
\hline Urban & 18.6 & 2.7 & \\
\hline
\end{tabular}

\section{Discussion}

The majority of the participants in this present study were females. Findings from studies conducted in South Africa and elsewhere have indicated that females are more likely to actively seek health care compared to their male counterparts (Eyassu et al., 2016; Mayeye, Mayeye, Lewis, \& Oguntibeju, 2010; Nyambura, 2009; UNAIDS, 2016). For example, in South Africa, men who present for ART look sicker on the average than women, suggesting delays by men on being tested or care seeking once tested (Bekker, Myer, Orre, Lawn, \& Wood, 2006). The authors further indicated that girls aged 15-24 years are more prone to HIV infection than boys of similar age category. Sexual abuse by older men has been identified as a common contributory factor to acquiring HIV infection in South Africa (Mchunu, Peltzer, Tutshana, \& Seutlwadi, 2012).

The majority of the participants in this present study were between 22 to 24 years. These findings concur with several studies concerning ART adherence among adolescents and youths (Fick, Fairlie, Moultrie, Woollett, Pahad, Thomson, \& Pleaner, 2015; Kagee et al., 2011; Kim et al., 2014). The increased number of youths in this age category of 22 to 24 years probably suggest that some of the youths had completed secondary education, and were unemployed while others dropped out before completing schooling. Some of the adolescents and youths within this age group drop out of schooling because of unplanned pregnancies, and the incidence of HIV is high because 
of young people indulging in risky sexual behaviours (Dawood, 2015) These findings are concurrent with other studies (Eyassu et al., 2016; Semvua et al., 2017; Nachega, Morroni, Zuniga, Schechter, Rockstroh, Solomon, \& Sherer, 2012). According to HBM, level of education, age, structural variables, and knowledge about HIV all have positive influence on compliance (Hayden, 2009).

Concerning participants' self-efficacy and adherence to ART, the findings revealed that the majority of the participants do not have a hard time remembering to take their dose of medication (80.6\%). The participants maintained that they are always determined to do anything to take their medication on schedule, and as prescribed. Findings from this study concur with several studies conducted elsewhere (Rudy et al., 2009; Johnson et al., 2007; Adefolalu et al., 2014; Parsons, Rosof, \& Mustanski, 2008; UNAIDS, 2016). According to HBM, the construct of self-efficacy, or confidence, hinges on a belief in oneself, a self-belief that one can accomplish even the most difficult tasks, such as taking the often-complex regimens of HAART (Bandura \& Ramachaudran, 1994). Self-efficacy for treatment adherence has been identified as an important correlate of medication adherence in the treatment of HIV and other medical conditions (Johnson, Neilands, Dilworth, Morin, Remien, \& Chesney, 2007).

In this study, there was no relationship between demographic variables and perceptions of treatment benefits. The HBM states that demographic variables such as age, gender, marital status, education level and ethnicity are the modifying factors influencing a person's perceptions about a disease. For example, an unmarried person may adhere better to treatment regiments than married people, because they are free to make their choices and decisions (Asare \& Sharma, 2012). Consistent with Stanhope and Lancaster (2005), socio-demographic factors generally did not entirely predict ART adherence behaviour. However, other studies have shown that younger age (Eyassu et al., 2016; Williams et al., 2006), being female, under 35 years, single, and having higher educational status (Uzochukwu, Onwujekwe, Onoka, Okoli, Uguru, \& Chukwuogo, 2009; Semvua et al., 2017; Kagee et al., 2011; Azia et al., 2016), significantly affect poorer adherence to ART. Contrastingly, Weiser, Wolfe and Bangsberg (2003) found no association between gender and adherence to ART.

Regarding perceived benefits and adherence to ART, participants agreed that following treatment plan will help them to be healthy and have realised that strict adherence to the treatment plan is essential for ARV treatment to be effective (143:69.4\%) (Glanz, Lewis, \& Rimer, 2002). The findings from this study are consistent with findings from other studies (Hudelson \& Cluver, 2015; Ndou, Maputle, \& Risenga, 2016; Tuhadeleni, Gary, Ashipala, \& Nuuyoma, 2016).

\subsection{Limitations}

Most participants were recruited from two clinics that were known to be Youth Friendly Clinics, while others were from ordinary primary health clinics. This situation might have caused different opinions related to aspects of care related to clinic. The use of a convenience sampling method might have compromised the results; hence, results cannot be generalized to other adolescents and youths in other regions within the Eastern Cape Province. Nevertheless, the finding of the study provides baseline information on adherence to ART medications benefits and self-efficacy among adolescents and youths in the Eastern Cape Province, which could be useful to inform health interventions tailored to adolescents and youths concerning adherence to ART.

\section{Conclusion}

The study adds credence to Health Belief Model postulation that perception of benefits in intervention can result to better adherence to ART. Perceived benefits could be a predictor of an action, or can influence adherence to medications. Self-efficacy is a predictor of adherence to ART by adolescents and youths. The findings of this study confirm these assertions. Therefore, it is imperative for health providers to ensure client counselling for the facilitation of sustainable adherence to ART.

\section{Competing Interests Statement}

The authors declare that there are no competing or potential conflicts of interest.

\section{References}

Adefolalu, A., Nkosi, Z., Olorunju, S., \& Masemola, P. (2014). Self-efficacy, medication beliefs and adherence to antiretroviral therapy by patients attending a health facility in Pretoria. South African Family Practice, 56(5), 281-285. https://doi.org/10.1080/20786190.2014.975476

Asare, M., \& Sharma, M. (2012). Role of health belief model on sexual communication among African immigrants. American Journal of Health Studies, 27(2). https://doi.org/10.1353/hpu.2013.0020

Azia, I. N., Mukumbang, F. C., \& Van Wyk, B. (2016). Barriers to adherence to antiretroviral treatment in a regional hospital in Vredenburg, Western Cape, South Africa. Southern African Journal of HIV Medicine, 
17(1). https://doi.org/10.4102/sajhivmed.v17i1.476

Bandura, A., \& Ramachaudran, V. S. (1994). Self-efficacy. Encyclopedia of human behavior. VS Ramachaudran (Ed.)

Barclay, T. R., Hinkin, C. H., Castellon, S. A., Mason, K. I., Reinhard, M. J., Marion, S. D., .. Durvasula, R. S. (2007). Age-associated predictors of medication adherence in HIV-positive adults: Health beliefs, self-efficacy, and neurocognitive status. Health Psychology, 26(1), 40. https://doi.org/10.1037/0278-6133.26.1.40

Bekker, L. G., Myer, L., Orrell, C., Lawn, S., \& Wood, R. (2006). Rapid scale-up of a community-based HIV treatment service: programme performance over 3 consecutive years in Guguletu, South Africa. South African Medical Journal, 96(4), 315-320.

Centers for Disease Control and Prevention (CDC). (2012). Integrated prevention services for HIV infection, viral hepatitis, sexually transmitted diseases, and tuberculosis for persons who use drugs illicitly: summary guidance from CDC and the US Department of Health and Human Services. Morbidity and Mortality Weekly Report. Recommendations and reports, 61(RR-5), p.1.

Dawood, H. (2015). Adolescent HIV treatment issues in South Africa. South African Medical Journal, 105(11), 953. http://dx.doi.org/10.7196/SAMJ.2015.v105i11.10130

DiMatteo, M. R., Hays, R. D., Gritz, E. R., Bastani, R., Crane, L., Elashoff, R., ... Marcus, A. (1993). Patient adherence to cancer control regimens: Scale development and initial validation. Psychological Assessment, 5(1), 102. https://doi.org/10.1037/1040-3590.5.1.102

Eyassu, M. A., Mothiba, T. M., \& Mbambo-Kekana, N. P. (2016). Adherence to antiretroviral therapy among HIV and AIDS patients at the Kwa-Thema clinic in Gauteng Province, South Africa. African Journal of Primary Health Care \& Family Medicine, 8(2), 1-7. https://doi.org/10.4102/phcfm.v8i2.924

Fick, C. Fairlie, L., Moultrie, H., Woollett, N., Pahad, K., Thomson, K., \& Pleaner M. (2015). Working with adolescents living with HIV: A Handbook for Healthcare Providers. Johannesburg: Wits RHI and Southern African HIV Clinicians Society.

Glanz, K., Rimer, B. K., \& Lewis, F. M. (2002). Health behavior and health education: theory, research, and practice (pp. 45-66). San Francisco: Jossey-Bass, 2002.

Hayden, J. A. (2009). Introduction to Health Behaviour Theory. Sudbury: Jones and Bartlett.

Hudelson, C., \& Cluver, L. (2015). Factors associated with adherence to antiretroviral therapy among adolescents living with HIV/AIDS in low-and middle-income countries: a systematic review. AIDS Care, 27(7), 805-816. https://doi.org/10.1080/09540121.2015.1011073

Johnson, M. O., Neilands, T. B., Dilworth, S. E., Morin, S. F., Remien, R. H., \& Chesney, M. A. (2007). The role of self-efficacy in HIV treatment adherence: validation of the HIV Treatment Adherence Self-Efficacy Scale (HIV-ASES). Journal of Behavioral Medicine, 30(5), 359-370. https://doi.org/10.1007/s10865-007-9118-3

Kagee, A., Remien, R. H., Berkman, A., Hoffman, S., Campos, L., \& Swartz, L. (2011). Structural barriers to ART adherence in Southern Africa: challenges and potential ways forward. Global Public Health, 6(1), 83-97. https://doi.org/10.1080/17441691003796387

Kim, S. H., Gerver, S. M., Fidler, S., \& Ward, H. (2014). Adherence to antiretroviral therapy in adolescents living with HIV: systematic review and meta-analysis. AIDS (London, England), 28(13), 1945. https://doi.org/10.1097/QAD.0000000000000316

Mayeye, F. B., Lewis H. A., \& Oguntibeju, O. O. (2010). An assessment of adolescent satisfaction with reproductive primary health care services in the Eastern Cape Province, South Africa. West Indian Medical Journal, 59(3), 274-279.

Mchunu, G., Peltzer, K., Tutshana, B., \& Seutlwadi, L. (2012). Adolescent pregnancy and associated factors in South African youth. African health sciences, 12(4), 426-434. https://doi.org/10.4314/ahs.v12i4.5

Munro, S., Lewin, S., Swart, T., \& Volmink, J. (2007). A review of health behaviour theories: how useful are these for developing interventions to promote long-term medication adherence for TB and HIV/AIDS? BMC Public Health, 7(1), 104. https://doi.org/10.1186/1471-2458-7-104

Nachega, J. B., Morroni, C., Zuniga, J. M., Schechter, M., Rockstroh, J., Solomon, S., \& Sherer, R. (2012). HIV treatment adherence, patient health literacy, and health care provider-patient communication: results from the 
2010 AIDS Treatment for Life International Survey. Journal of the International Association of Physicians in AIDS care, 11(2), 128-133. https://doi.org/10.1177/1545109712437244

Ndou, T. V., Maputle, S. M., \& Risenga, P. R. (2016). HIV-positive patients' perceptions of care received at a selected antiretroviral therapy clinic in Vhembe district, South Africa. African Journal of Primary Health Care \& Family Medicine, 8(2), 1-6. https://doi.org/10.4102/phcfm.v8i2.926

Parsons, J. T., Rosof, E., \& Mustanski, B. (2008). Medication adherence mediates the relationship between adherence self-efficacy and biological assessments of HIV health among those with alcohol use disorders. AIDS and Behavior, 12(1), 95-103. https://doi.org/10.1007/s10461-007-9241-8

Quinn, T. C. (2001). The global HIV pandemic: Lessons from the past and glimpses into the future. The John Hopkins AIDS Report. Retrieved from http://www.hopkins-aids.edu/publications/report/jan01 4.html

Rudy, B. J., Murphy, D. A., Harris, D. R., Muenz, L., \& Ellen, J. (2009). Patient-related risks for non-adherence to antiretroviral therapy among HIV-infected youth in the United States: a study of prevalence and interactions. AIDS Patient Care and STDs, 23(3), 185-194. https://doi.org/10.1089/apc.2008.0162

Semvua, S. K., Orrell, C., Mmbaga, B. T., Semvua, H. H., Bartlett, J. A., \& Boulle, A. A. (2017). Predictors of non-adherence to antiretroviral therapy among HIV infected patients in northern Tanzania. PloS one, 12(12), e0189460. https://doi.org/10.1371/journal.pone.0189460

Stanhope, M., \& Lancaster, J. (2005). Community and public health nursing. 5th edition. Philadelphia: Mosby.

Tanner, A. E., Philbin, M. M., Duval, A., Ellen, J., Kapogiannis, B., Fortenberry, J. D., \&, Adolescent Trials Network for HIV/AIDS Interventions (2014). Youth friendly" clinics: Considerations for linking and engaging HIV-infected adolescents into care. AIDS Care, 26(2), 199-205. https://doi.org/10.1080/09540121.2013.808800

Tuhadeleni, O., Gary, E., Ashipala, D. O., \& Nuuyoma, V., (2016). The perceptions of HIV-Positive patients (ART patients) on Anti-Retroviral Therapy (ART), Treatment Supporters and Health Care Workers with Regard to their role in ART adherence at ART Clinics in the Intermediate Hospital Oshakati, Namibia. Health Science Journal, 10(5). https://doi.org/10.14419/ijm.v5i1.6999

UNAIDS. (2016). Joint United Nations Programme on HIV/AIDS, Global AIDS update 2016. Geneva: UNAIDS.

Uzochukwu, B. S. C., Onwujekwe, O. E., Onoka, A. C., Okoli, C., Uguru, N. P., \& Chukwuogo, O. I. (2009). Determinants of non-adherence to subsidized anti-retroviral treatment in southeast Nigeria. Health Policy and Planning, 24(3), 189-196. https://doi.org/10.1093/heapol/czp006

Weiser, S., Wolfe, W., Bangsberg, D., Thior, I., Gilbert, P., Makhema, J. ... Marlink, R. (2003). Barriers to antiretroviral adherence for patients living with HIV infection and AIDS in Botswana. Journal of Acquired Immune Deficiency Syndromes, 34(3), 281-288. https://doi.org/10.1097/00126334-200311010-00004

Williams, P. L., Storm, D., Montepiedra, G., Nichols, S., Kammerer, B., Sirois, P.A., Farley, J., \& Malee, K. (2006). Predictors of adherence to antiretroviral medications in children and adolescents with HIV infection. Pediatrics, 118(6), .e1745-e1757. https://doi.org/10.1542/peds.2006-0493

\section{Copyrights}

Copyright for this article is retained by the author(s), with first publication rights granted to the journal.

This is an open-access article distributed under the terms and conditions of the Creative Commons Attribution license (http://creativecommons.org/licenses/by/4.0/). 